\title{
Mechanisms of preventative and therapeutic role of probiotics in different allergic and autoimmune disorders
}

\author{
Öner Özdemir \\ Division of Allergy/Immunology, Department of Pediatrics, Research and Training Hospital of Sakarya University, Faculty of Medi- \\ cine, Sakarya University, Adapazarı, Türkiye; ozdemir_oner@hotmail.com \\ Received 10 June 2013; revised 8 July 2013; accepted 22 July 2013 \\ Copyright (C) 2013 Öner Özdemir. This is an open access article distributed under the Creative Commons Attribution License, which \\ permits unrestricted use, distribution, and reproduction in any medium, provided the original work is properly cited.
}

\begin{abstract}
The prevalence of allergic and autoimmune diseases has been increasing from the last decades of 20th century. Intestinal microflora contributes to antigen exposure in early life and is one of the most abundant sources of early immune stimulation as well as adaptation. Because allergic and autoimmune responses manifest early in life, there has been obvious interest in the potential benefits of modifying the gastrointestinal flora by using probiotic supplementation. So far, there have been several studies to address the role of probiotics in primary prevention and therapy, with a reported suspicious reduction in the incidence of atopic and autoimmune diseases. Here, our aim is to evaluate the available knowledge of mechanisms of preventative and therapeutic role of probiotics in different allergic and autoimmune disorders. Promising mechanisms of probiotic effects may be categorized as local and systemic effects. Local influences of probiotics potentially include reduction of gut permeability and systemic penetration of antigens, increased local immunoglobulin A production, and alteration of local inflammation or tolerance induction. Some possible systemic effects consist of antiinflammatory effects mediated by Th17 cells and Toll-like receptors, Th1 skewing of responses to allergens, activation of tolerogenic dendritic cells, in addition to T-regulatory cell production.
\end{abstract}

Keywords: Probiotics; Allergic Disease; Autoimmune Disease; Atopic Dermatitis; Asthma

\section{INTRODUCTION}

The gastrointestinal tract of the newborn baby is sterile.
Soon after birth, however, it is colonized by many different microorganisms. The newborn is first colonized by microbes at birth. The colonization of the gut that begins promptly after birth is affected by mode of delivery, early feeding strategies and the hygienic conditions around the child (the early environment). The colonizing bacteria originate mainly from the mother's gut and vaginal tract [1]. Mode of delivery, either vaginal or through caesarean section, also has a major impact on early colonization patterns of the infant gut. For instance, children born by cesarean section are colonized with Bifidobacteria and Lactobacilli later than vaginally delivered children, and are shown to have more frequent respiratory allergies [2]. After delivery, breastfeeding continues to enhance the original inoculum by the introduction of specific lactic acid bacteria, Bifidobacteria and bacteria from the mother's skin, all of which enable the infant gut microbiota that is dominated by Bifidobacteria. Breast milk also contains plentiful indigestible oligosaccharides, which pass through the whole intestine and promote the growth and activity of commensal bacteria; composed mainly of Bifidobacteria [3]. The greatest differences between breastfed and formula-fed infants appear to be in lactic acid bacteria and Bifidobacteria colonization. Usually, Bifidobacteria appear after birth and, within a week, are reported as the dominant bacterial group, with Bifidobacterium infantis/longum/breve being the most common species in breast-fed infants [4]. In addition, Lactobacillus acidophilus is the most common Lactobacillus in the feces of breast-fed infants. Formula-fed infants, on the other hand, tend to have a flora that is more complex, consisting mostly of Coliforms and Bacteroides, with significantly lower the prevalence of Bifidobacteria [5]. After weaning, the microflora of children begins to resemble that of adults, with increased Bacteroides, Veillonella, and Fusobacterium [6]. These bacteria set the basis for gut microbiota development and modulation, 
along with environmental exposures such as antibiotic administration.

Colonization is complete after around one week, but the numbers and species of intestinal bacteria fluctuate markedly during the first several months of life. The composition of the gut microbiota differs between healthy and allergic infants and even in countries with a high and low prevalence of allergies. In the case of allergy, the rationale for modulating the intestinal microbiota is supported by observations that allergic children have a different microbiota composition than healthy infants. The main changes associated with allergic trait are less frequent colonization with Lactobacilli and lower counts of Bifidobacteria [7]. Furthermore, other studies have also shown that early colonization with potentially more pathogenic bacteria such as Clostridium difficile and Staph. aureus is more likely to occur in children who go on to develop allergy. In addition to these quantitative differences in the Bifidobacterium microbiota, qualitative differences have also been observed. Infants with atopic disease have been found to have a more adult type Bifidobacterium microbiota with high prevalence of Bifidobacterium adolescentis. Healthy infants, on the other hand, were found to be colonized mainly by Bifidobacterium bifidum, typical for breast-fed infants [5,6]. The Bifidobacteria from infants with atopic disease were found to induce a higher secretion of proinflammatory cytokines in vitro, whereas the Bifidobacteria from healthy infants induced the secretion of more anti-inflammatory cytokines. Also, Bifidobacteria of dairy origin stimulated more anti-inflammatory and less inflammatory cytokines than Bifidobacteria from allergic infants. In addition to differing in their induction of cytokines, Bifidobacteria from allergic and healthy infants also exhibited different in vitro adhesion to Caco-2 tissue culture cells and intestinal mucus. This difference in adhesion to the intestinal mucosa may result in a different or reduced stimulation of the immune system through the gut-associated lymphoid tissue [8]. Lower counts of Bifidobacteria have been reported in atopic vs. nonatopic children preceding allergen sensitization. Bifidobacteria are hypothesized to more effectively promote tolerance to nonbacterial antigens, primarily by inhibiting the development of a Th2-type (proallergic) response. In a recent study, a positive change in stool colonization in atopic infants supplemented with Bifidobacterium lactis has been shown with a decrease of Bacteroides and $E$. coli in the stool. Most interestingly, serum IgE correlated with $E$. coli counts, and in highly sensitized infants, IgE correlated with Bacteroides counts [9]. Thus, certain probiotics seem to influence the gut's allergen-stimulated inflammatory response and provide a barrier effect against antigens that might otherwise ultimately lead to systemic allergic symptoms (such as eczema). The en- hanced presence of these probiotic bacteria in the intestinal microbiota seems to correlate with protection against atopy $[7,10]$. Based on these data, "harmless" microbial agents that are probiotics have been presently tested for their efficacy in the prevention and therapy of allergy in infants [11-13].

The new version of "hygiene hypothesis" proposes that reduced exposure to environmental and/or enteric stimuli, including microbes, underlies the rising incidence of childhood atopic as well as autoimmune diseases. This hypothesis is supported by data that highlight the importance of infant exposure to environmental microbes for appropriate development of the immune system [14]. This might explain the observation that administration of microbes or their components inhibits autoimmune diseases in animals such as insulin dependent diabetes mellitus or autoimmune type 1 diabetes $[15,16]$. Recent studies, however, have revealed that exposure of genetically diabetes-susceptible animals to certain microbes or microbial agents at an early age prevent the induction and progression of disease. This suggests that microbes may act to modulate the immunological status or immune repertoire of an individual genetically programmed for type 1 diabetes away from an autoimmune response [17]. Immunization with microbial agents at an early age may offer an important new direction for the immunotherapy of type 1 diabetes $[17,18]$. The protective effect of a probiotic and a bacterial extract was reported on the onset of diabetes in non-obese diabetes mice [19]. These findings raise the possibility of using live, nonpathogenic microbes (for example, probiotics) or microbial components to modulate or "re-educate" the immune system.

Probiotic intestinal flora contributes to microbial antigen exposure in early life and is one of the most abundant sources of early immune stimulation. Because allergic and auto-immune responses manifest early in life, there has been obvious interest in the potential benefits of modifying the gastrointestinal flora by using probiotic supplementation. So far, there have been only several studies to address the role of probiotics in primary prevention/therapy, with a reported suspicious reduction in the incidence of atopic and autoimmune diseases. The role of probiotics in the prevention of allergy and autoimmunity development has still remained controversial [13], and there has been an urgent call for similar studies to address this further. In this review article, we will try to highlight the issues with probiotics in the therapy/ prevention of atopy/autoimmunity and future of this therapy. Firstly, the ethiopathogenesis of allergic/autoimmune disease and then its relation to gut and environmental microbiota (hygiene) are considered before discussing the mechanisms of probiotic effect and the beneficial effects that they may confer to individuals with 
allergic/autoimmune disease. Lastly, under the light of recent literature probiotic use in the therapy and prevention of atopic as well as autoimmune diseases is being discussed in detail.

\subsection{Ethiopathogenesis of Allergic and Autoimmune Disease}

Development of the child's immune system tends to be directed toward a T-helper 2 (Th2) phenotype in infants, whereas postnatal maturation is associated with gradual inhibition of Th2 and increasing Th1 affinity [20]. Thus, immature Th2-dominant neonatal responses must undergo environment-driven maturation via microbial contact in the early postnatal period to prevent development of childhood allergic and/or autoimmune diseases. Nevertheless, nowadays the increased use of antimicrobial medication, the consumption of sterile food, and reduced family size that result in lower rates of infection during childhood also reduce early contact to microbes. Among several other phenomena, the present increase in allergic or autoimmune diseases seen in the industrialized countries has been attributed, to a relative lack of microbial stimulation of the infantile gut immune system and the exaggerated hygiene of the typical western lifestyle during early childhood. And this is known as the "hygiene hypothesis" [14].

The other hypotheses in the allergic and autoimmune disease pathogenesis besides "hygiene-old friends-hypothesis", such as bystander immunoregulation and regulatory $\mathrm{T}$ cell (Treg) defects are briefly discussed below as well [21]. Because of our long association with environmental organisms (old friends), they are recognized by the innate immune system as harmless or, in the case of some helminths, treated as "friends" because a response would merely lead to immunopathology [14]. Therefore, rather than priming aggressive immune responses, these organisms prime immunoregulation. They do it by inducing an unusual pattern of maturation of Dendritic cells such that these retain the ability to drive Treg. Tolllike receptor (TLR)-2 may be involved for helminths and TLR-9 for lactobacilli. It is interesting that polymorphisms of NOD2 (an intracellular receptor for bacterial peptidoglycan) are linked to increased susceptibility to both Crohn's disease and asthma [22]. Thus an extension of the "hygiene hypothesis" mechanism suggests that in an environment that less actively primes Treg activity, immunoregulatory disorders will occur first in those individuals whose innate immune systems are least efficient at driving Treg.

The increased regulatory dendritic cells and Treg induced by "old friends" then lead to two immunoregulatory mechanisms mediated in part by release of IL-10 and TGF- $\beta$. Firstly, continuing exposure to "old friends" will cause continuous background activation of Treg specific for the "old friends" themselves, resulting in a constant background of "bystander suppression" [23]. This mechanism has been demonstrated in a model of colitis. Secondly, regulatory dendritic cells inevitably sample self and gut contents and so induce Treg specific for the target antigens of the groups of chronic inflamematory disorder. These mechanisms may be aborted when there are legitimate "danger" signals. For example, Treg function can be turned off by appropriate "danger signals" in vitro [24].

The unifying hypothesis explaining the simultaneous increase in Th2-mediated allergies and Th1-mediated autoimmunity is that modern living conditions can lead to defective maturation of Treg and regulatory Antigen Presenting Cell or regulatory dendritic cells [25]. Therefore, rather than Th1/Th2 balance, the crucial factor is likely to be the effector $\mathrm{T}$ cells/Treg balance. Thus diminished immunoregulation can lead to inappropriate immune responses to allergens, gut contents, or self. In the absence of optimal levels of immunoregulation, the individual may develop a Th1-/Th2-mediated inflammatory disorder, depending on his/her own particular Th1/ Th2 bias, immunological history, and genetic background. Evidence to confirm this hypothesis has come from studies of allergic disorders, multiple sclerosis and autoimmune polyglandular syndromes [21].

\subsection{Any Role for Hygiene (Environmental/ Intestinal Microbiota) in Allergic and Autoimmune Disease Development?}

According to the "hygiene (old friends) hypothesis", the decreasing incidence of infections in developed and developing countries is at the origin of the increasing incidence of allergic diseases [14]. New practices, introduced as a result of industrialization, such as childbirth by surgical delivery, ingestion of pasteurized food, cleaner homes, and indiscriminate use of antibiotics and so on, have led in recent years to the replacement of probiotics by other microorganisms that are not as well adapted to the microenvironments of the human body. The hygiene hypothesis is based upon epidemiological data, particularly migration studies, showing that subjects migrating from a low-incidence of infections to a high-incidence country acquire the allergic/autoimmune disorders with a high incidence at the first generation as well. Therefore, it was possible to extend the old hypothesis from the field of allergy, where it was formulated, to those of autoimmune diseases such as type 1 diabetes or multiple sclerosis [25]. However, some data and others showing a correlation between high autoimmune disease incidence and high socio-economic level do not prove a causal link between infections and immune disorders. Part of the increased incidence of these diseases may be somewhat attributed to better diagnosis 
or improved access to medical facilities in economically developed countries. However, this cannot explain the marked increase in immunological disorder prevalence that has occurred over such a short period of time in those countries, particularly for diseases which can be diagnosed easily, such as type 1 diabetes or multiple sclerosis. Based on hygiene hypothesis, the sudden change in human intestinal microflora may importantly contribute to the rise in the incidence of autoimmune and allergic diseases, observed in the last half of 20th century. More than 17 bacterial families encompassing 500 different microbial species can be found in human adults. These commensal bacteria regulate a myriad of host processes and provide several nutrients to their host and their symbionts within the microbial community. In healthy individuals these relationships are thought to occur in equilibrium. However, disruption of this equilibrium may contribute to a variety of conditions including autoimmune, inflammatory bowel and atopic disease [26, 27]. This connection is gaining credibility as associations between gut microbiota and either the risk for or presence of a variety of specific human diseases is demonstrated.

The diversity of intestinal bifidobacteria could be a prospective target for using probiotics in the results management of IgE-mediated allergic disorders including Japanese cedar pollinosis. Correspondingly, a study by Kubota et al. suggests that lower diversity of intestinal Bifidobacterium species might be a pathological aspect of Japanese cedar pollinosis. The serum IgE concentration of Japanese cedar pollinosis patients with more than 3 detectable Bifidobacterium species was significantly lower than that of patients with less than 2 detected species. Another randomized double-blind, placebo-controlled trial by the same team was conducted to ascertain the intestinal microbiota-altering properties of Lactobacillus rhamnosus GG (LGG) and Lactobacillus gasseri in patients with Japanese cedar pollinosis. Stabilization of intestinal microbiota by selected probiotic strains such as LGG and Lactobacillus gasseri could be beneficial to homeostasis of the intestinal microbiota and useful in the management of Japanese cedar pollinosis [28].

Accordingly, the pathogenesis of autoimmune diseases has been recently thought to involve an interaction between genetically determined host susceptibility, the enteric microbiota and dysregulated immune response. Interactions between the intestinal environment, barrier function, and immune system have been shown to have a major impact in the rate of autoimmunity development. Disruption of intestinal barrier function and aberrant mucosal immune activation has been implicated in a variety of diseases within and outside of the gastrointestinal tract [26-29]. The penetration of gut bacterial antigens into lymphoid tissues is one of the suggested initial factors leading to a loss of tolerance towards self components in genetically predisposed individuals. With this model in mind, recent studies have shown a link between diet, composition of intestinal microbiota, and pathogenesis of autoimmune diseases. Furthermore, this new paradigm subverts traditional theories underlying autoimmunity development, which are mainly based on molecular mimicry, and suggests that the autoimmune process can be arrested if the interplay between genes and environmental triggers is prevented by re-establishing intestinal barrier function [15].

A hypothesis previously has been proposed involving a trio of interacting factors that may create a "perfect intestinal/environmental storm" for autoimmune diseases such as type 1 diabetes development. These factors include: 1) an aberrant intestinal microbiota; 2) a "leaky" intestinal mucosal barrier; and 3) altered intestinal immune responsiveness [16]. In support of this model, modulation of type 1 diabetes pathogenesis in animal models has proved successful through early intervention with a variety of dietary alterations. Indeed, the administration of a hydrolyzed casein diet or the administration of antibiotics has strengthened the hypothesis that an aberrant microbiota could accelerate disease development. More importantly, this is not a phenomenon that occurs only in rodent models of diabetes, as very recent studies have noted that humans with a propensity to develop type 1 diabetes as well as other autoimmune diseases possess an abnormal intestinal barrier; the so called "leaky gut" [15, 30]. Together with the gut-associated lymphoid tissue and the neuroendocrine network, the intestinal epithelial barrier, with its intercellular tight junctions, controls the equilibrium between tolerance and immunity to nonself-antigens. Other modulators of tight junction proteins such as certain probiotics may also play a role in modulation of "intestinal leakiness" [27,28,31].

\section{WHAT ARE PROBIOTICS?}

Probiotic is derived from the Greek word meaning "supporting/favoring life or for life". The works of Metchnikoff and Tissier were the first to make scientific suggestions about the probiotic use of bacteria, even if the word "probiotic" was not coined until 1960, to name substances produced by microorganisms which promoted the growth of other microorganisms [12]. The year 2012 marks the 105nd year since Eli Metchnikoff suggested that the consumption of lactic acid bacteria may benefit the human host's immune system [11]. Although probiotics are mainly thought to be represented by lactic acid bacteria, probiotic activity has been found to be associated with Lactobacilli (LGG, gasseri, salivarius), Lactococci, Bifidobacteria (bifidum, longum, infantis), Streptococcus 
(thermophilus, cremoris, faecium, infantis), Enterococcus (faecium), nonpathogenic E. coli (Nissle 1917), Bacillus coagulans and Saccharomyces strains (boulardii and cerevisiae) $[11,12]$. The most popular lactic acid bacteria are members of the genera Lactobacilli and Lactococci, which have a long history of safe use. Lactobacillus acidophilus is the most well-known and one of the most important probiotics for the health of the small intestine.

Probiotics are usually isolated from the commensal microflora that inhabits the skin and mucosas. And they represent the species of viable microorganisms (bacteria or yeasts) that have a clear beneficial effect on the health of the host thru establishing a true symbiotic relationship with humans for the longest time. Probiotics are first described as selective nonpathogenic living microorganisms or components of bacteria in food supplements, including some commensal bacterial flora, which have beneficial effects on host health and disease prevention and/or treatment $[27,28]$. However, experts have debated how to define probiotics. One widely used definition, developed by the World Health Organization and the Food and Agriculture Organization of the United Nations, is that probiotics are "live microorganisms, which, when administered in adequate amounts, confer a health benefit by producing gut microflora on the host". Probiotics are also defined as "mono- or mixed cultures of live microorganisms which, when applied to animal or man, beneficially affect the host by improving the properties of the indigenous microflora" [12]. Simply, probiotics are ingested live microbes that can modify intestinal microbial populations in a way that benefits the host.

There are several generally accepted characteristics that identify probiotic bacteria. Probiotics are microbial organisms of human origin and having generally regarded as safe status; remain viable and stable after culture, manipulation, and storage before utilization; survive gastric, biliary, and pancreatic digestion (acid and bile stability); are able to induce a host response once they enter the intestinal microbial ecosystem (adherence to intestinal cells); and yield a functional or clinical benefit (ability to produce antimicrobial substances and antagonize against pathogenic bacteria and/or ability to modulate the immune response) to the host when consumed [11-13,27,28].

The number of commercially available products that are supplemented with probiotics is rising. Dairy products that contain probiotics are sold in every supermarket and probiotic food supplements (for example, capsules, tablets, and powders) can be purchased in pharmacies or via the internet. For infants, infant formulas containing probiotics are also currently available. Live probiotic cultures are available in fermented dairy products and probiotic fortified foods. Examples of foods containing live probiotics are yoğurt, fermented and unfermented milk, miso, tempeh, and some juices and soy beverages. However, tablets, capsules, powders and sachets containing the bacteria in freeze dried form are also available.

\section{CAN PROBIOTICS REALLY PREVENT AND/OR TREAT ANY TYPE OF ALLERGIC OR AUTOIMMUNE DISEASE?}

The interest in probiotic therapeutic potential in allergic disorders stemmed from the fact that they have been shown to improve intestinal permeability and reduce inflammatory cytokines. Such effects would be desirable in treating allergic as well as autoimmune disorders [10, 32]. Therefore, several studies have been designed to examine the efficacy of probiotics in many allergic and autoimmune diseases. Experimental and clinical trials of probiotic use as capable preventive and therapeutic strategy in different diseases varying from allergic to autoimmune disease have recently reported. Over 50 randomized, double-blind, placebo-controlled human clinical trials have been conducted so far to study the effects of various probiotics on treatment and prevention of allergic/autoimmune diseases. In the first-time study done by Majamaa and Isolauri in 1997, the administration of LGG to highly selected patients (age $<2$ years, challengeproven cow's milk allergy, and mild-to-moderate eczema) significantly improved the total SCORAD score [33]. Later the Finnish study of Kalliomaki was the first report to describe that the frequency of eczema in neonates treated with LGG was half that of the placebo [34]. However, these results recently have been questioned by some other trials, which reported no difference in the development and therapy of allergy in neonates supplemented with LGG or other probiotics.

Proof of principle of the hygiene hypothesis is supported by animal models and to a lesser degree by intervention trials in humans. The incidence of spontaneous type 1 diabetes is directly correlated with the sanitary conditions of the animal facilities, for both the non-obese diabetes mouse and the bio-breeding diabetes-prone rat: the lower the infectious burden, the higher the disease incidence [15-19,25]. Diabetes has a very low incidence and may even be absent in non-obese diabetes mice bred in "conventional" facilities, whereas the incidence is close to $100 \%$ in female mice bred in specific pathogenfree conditions [35]. Furthermore, bio-breeding diabetesprone rats subject to Cesarean derivation have been noted to develop accelerated disease due to lack of contamination with microbiota in birth canal [36]. Taken together, these data from animal models open new therapeutic perspectives in the prevention of allergic and autoimmune diseases by using probiotics. Consequently, 
dietary manipulation for $\beta$-cell autoimmunity in infants at increased risk of type 1 diabetes was performed in a pilot study. This pilot study, called as PRODIA (probiotics for the prevention of $\beta$-cell autoimmunity in children at genetic risk of type 1 diabetes), included 200 children with genetic risk for type 1 diabetes. However, the prevalence of type 1 diabetes-associated autoantibodies among the study subjects at 6,12 , and 24 months of age was at levels close to the expected [15].

As seen above, preventive or therapeutic effect of probiotics in allergy and autoimmune disease could not be consistently established for now. One of the aims of this review is to delineate current knowledge of probiotics, including the key mechanisms of probiotic effects as well as their real preventative/therapeutic role in both diseases.

\subsection{Experimental and Clinical Studies Showing Mechanisms of Probiotics' Effects in Allergic and Autoimmune Diseases}

Although the beneficial effects of probiotics on wide variety of atopic diseases have been suggested, little is known about how probiotics modulate the immune system, atopic disease and autoimmunity development. Currently, only limited publications are available defining the effects of probiotics in murine or human models of atopy and autoimmunity. Therefore, it is important to explore the effect of probiotics in various experimental and clinical atopic and autoimmune disease models. Here, some experimental (animal) and clinical studies of probiotics under the recent literature gathered from Medline and Pubmed showing supposed mechanisms of probiotics' effects in atopic and autoimmune disease are being described below (as summarized in Table 1).

\subsubsection{Maturing Gut Barrier: Probiotic Regulation in Intestinal Epithelium and Upregulation of Host Immune Responses}

Recent data indicate that commensal intestinal microbiota represents a major modulator of intestinal homeostasis. Dysregulation of the symbiotic interaction between intestinal microbiota and the mucosa may result in a pathological condition with potential clinical repercussions. For instance, it is shown that mice reared in germ-free conditions have an underdeveloped immune system and have no oral tolerance. In contrast, pathogen-free mice are capable of reconstituting the bacterial flora with Bifidobacteria and tolerance development [37]. Likewise, based on the hygiene hypothesis, it has been theorized that changes in human intestinal microflora in developed societies cause an increase in the prevalence of autoimmune disease besides allergies. Regulation of intestinal microflora composition by probiotics may offer the possibility to influence the development of muco$\mathrm{sal} /$ systemic immunity as well as allergy and autoimmune disease development. Probiotics are used in allergic diseases, which have shown to be beneficial in some patients with atopic dermatitis and allergic rhinitis [13, 32]. Similarly, there is an increasing amount of data showing that intestinal microbiota changes could contribute to the modulation of immune-mediated disorders but evidence is still slim, except in inflammatory bowel disease. The case of probiotics in inflammatory bowel disease is more complex because of the possible local anti-inflammatory effect, which could explain the relief of symptoms without changes in disease progression. Following a number of uncontrolled studies in a small cohort of 14 pediatric patients with newly diagnosed ulcerative colitis, probiotic treatment induced a significant rate of remission and a lower relapse rate [38,39].

In addition to providing maturational signals for the gut-associated lymphoid tissue, probiotics balance the generation of pro- and anti-inflammatory cytokines in the gut. Some components of heat-treated LGG may have an ability to delay the onset and suppress the development of atopic dermatitis, probably through a strong induction of IL-10 in intestinal lymphoid organs and systemic levels [40]. After probiotic consumption, decrease in fecal $\alpha-1$ antitrypsin, serum TNF- $\alpha$, and changes in TGF- $\beta$ and other cytokines point to down-regulation of inflammatory mediators [41]. For instance, after a challenge study in infants allergic to cow's milk, fecal IgA levels were detected to be higher and serum TNF- $\alpha$ level were lower in the LGG applied group compared to the placebo [42]. Similarly, another study by Kirjavainen et al. suggested that Bifidobacterium lactis might modify gut microflora to alleviate early onset atopic eczema. And this modification was found to be compatible with reductions of serum TNF- $\alpha$ and fecal $\alpha-1$-antitrypsin levels as well as an increase in fecal IgA level [8].

Moreover, probiotic bacteria may counteract the inflammatory process by stabilizing the gut microbial environment and the permeability barrier of the intestine, and by enhancing the degradation of enteral antigens and altering their immunogenicity [43]. This gut-stabilizing effect of probiotics could be explained by the improvement by probiotics of the immunological barrier of the intestine through intestinal IgA responses, specifically $[44,45]$. Oral treatment with probiotic Lactobacillus johnsonii for a specific part of the weaning period was also shown to prevent the development of atopic dermatitis in model mice, NC/Nga, by modulating or accelerating the gut immune response with increased intestinal secretory IgA [46]. Consistent with these explanations, in children with food allergies, probiotics are shown to reverse increased intestinal permeability and to enhance frequently defective IgA responses $[42,47]$. 
Table 1. Various mechanisms for effects of probiotic strains in atopic and autoimmune disorders are shown from experimental (animal) and clinical (human) studies referred in this review text.

\begin{tabular}{|c|c|c|c|}
\hline References & Probiotic Strain & Effect of probiotic & Outcome \\
\hline & & Maturing Gut Barrier & \\
\hline Sudo et al. [37] & Bfdbm & Oral tolerance & $\uparrow$ \\
\hline Dotan et al. [39] & VSL\#3 & Local anti-inflammatory effect & $\uparrow$ \\
\hline Cebra et al. [41] & various & Decreased fecal $\alpha-1$ antitrypsin (local anti-inflammatory ) & $\uparrow$ \\
\hline Sistek et al. [42] & LGG & Increased Fecal IgA & $\uparrow$ \\
\hline Kaila et al. [44] & Lctbs & Intestinal permeability & $\downarrow$ \\
\hline \multirow[t]{2}{*}{ Isolauri et al. [45] } & LGG & Gut-stabilizing effect & $\uparrow$ \\
\hline & & Th1/Th2 Balance & \\
\hline Kim et al. $[30,55]$ & $\begin{array}{l}\text { Bfdbm lactis/bifidum; } \\
\text { Lctbs acidophilus }\end{array}$ & IL-10, IFN- $\gamma / \mathrm{IL}-4, \operatorname{IgE}$ & $\uparrow / \downarrow$ \\
\hline Sistek et al. [42] & LGG & IL-10 Production & $\uparrow$ \\
\hline Takahashi et al. [48] & Bfdbm longum & Th2 cytokines and IgE production & $\downarrow$ \\
\hline Maassen et al. [50] & Lctbs casei & IL-10 and Th1 cytokines production & $\uparrow$ \\
\hline Niers et al. $[52,78]$ & Bfdbm bifidum/infantis; LL & Th2 cytokines/IL-10 production & $\downarrow / \uparrow$ \\
\hline Kruisselbrink et al. [53] & Lctbs plantarum & IL-10 Production & $\downarrow$ \\
\hline West et al. [54] & Lctbs F19 & Th1/Th2 & $\uparrow$ \\
\hline Shida et al. [57] & Bfdbm lactis $\mathrm{Bb}-12$ or LGG & Antigen-specific IgE production & $\downarrow$ \\
\hline Watanabe et al. [58] & Lctbs delbrueckii subsp. lactis & Potent Th1 inducer & $\uparrow$ \\
\hline Hayashi et al. [59] & Enterococcus faecium & IgE production & $\downarrow$ \\
\hline Won et al. [60] & Lctbs plantarum & Th1/Th2 cytokines, IL-10 production & $\uparrow$ \\
\hline Ogawa et al. [61] & Lctbs casei subsp. casei & $\mathrm{IgE}$ production & $\downarrow$ \\
\hline Segawa et al. [63] & Lctbs brevis & IgE production & $\downarrow$ \\
\hline $\begin{array}{l}\text { Rosenfeldt et al. [68]; } \\
\text { Brouwer et al. }[69]\end{array}$ & Various & Th1/Th2 cytokines & $\leftrightarrow$ \\
\hline \multirow[t]{2}{*}{ Hart et al. [79] } & Bfdbm bifidum & IL-10 production & $\uparrow$ \\
\hline & & Serum Inflammatory Parameters & \\
\hline $\begin{array}{l}\text { Sistek et al. [42]; } \\
\text { Pessi et al. }[70]\end{array}$ & LGG & Inflammatory parameters & $\downarrow$ \\
\hline Maassen et al. [50] & Lctbs reuteri & Immunomodulation & $\uparrow$ \\
\hline Brouwer et al. [69] & various & Serum inflammatory parameters & $\leftrightarrow$ \\
\hline Betsi et al. [71] & various & Serum inflammatory parameters & $\downarrow$ \\
\hline Woo et al. [72] & Lctbs sakei & CCL17 and CCL27 & $\downarrow$ \\
\hline Marschan et al. [74] & various & CRP & $\uparrow$ \\
\hline Inoue et al. [73] & Lctbs johnsonii & Proinflammatory cytokines & $\downarrow$ \\
\hline So et al. [76] & Lctbs casei & Effect on Th17 cells & $\downarrow$ \\
\hline Lavasani et al. [77] & probiotics mixture & Th17 cytokines & $\downarrow$ \\
\hline
\end{tabular}


Development of Tolerogenic Dendritic Cells

\author{
Niers et al. [52,78,] \\ Braat et al. [49] \\ Hart et al. [79] \\ Smits et al. [80] \\ Kim et al. [31,55] \\ Schwartz et al. [21]; \\ Issazadeh-Navikas et al. [81] \\ Smits et al. [80] \\ Feleszko et al. [82] \\ Di Giacinto et al. [83] \\ Hacini-Rachinel et al. [84] \\ Kwon et al. [86] \\ Weise et al. [88]
}

Braat et al. [49]

Kruisselbrink et al. [53]

Hacini-Rachinel et al. [84]

Gerasimov et al. [89]

Chapat et al. [90]

Roessler et al. [91]

Hoarau et al. [94]

Forsythe et al. [95]

Aumeunier et al. [96]

\author{
Bfdbm bifidum \\ Lctbs rhamnosus \\ Bfdbm bifidum \\ Lctbs reuteri/casei
}

Bfdbm bifidum;

Lctbs acidophilus

various

Lctbs reuteri/casei

LGG, Bfdbm lactis (Bb-12)

VSL\#3

Lctbs casei

Probiotic mixture

E. coli Nissle

Lctbs rhamnosus

Lctbs plantarum

Lctbs casei

Lctbs acidophilus, Bfdbm lactis

Lctbs casei

Probiotic mixture

Bfdbm bifidum/infantis;

Lctbs salivarius

Lctbs reuteri

various
Prime neonatal Dendritic cell (most potent polarizer)

Modulates Dendritic cell function (function modulator)

Matures Dendritic cells (phenotype modulator)

Prime monocyte-derived Dendritic cell

Immunoregulation (T-reg Production)

Treg-associated TGF- $\beta$ production

$\uparrow$

IL-10-dependent, TGF- $\beta$-bearing Tregs $\uparrow$

Prime monocyte-derived Dendritic cell $\uparrow \uparrow$

TGF- $\beta$ production

IL-10-dependent, TGF- $\beta$-bearing Tregs

CD4+/CD25+-Tregs

Foxp3+-Tregs

Foxp3+-Tregs

T-cell Hyporesponsiveness

Peripheral hyporesponsiveness in CD4+-T cells

Inhibits specific T-cell responses

Lymphocyte Subpopulation Changes

$\begin{array}{cc}\text { CD8+-T cell } & \downarrow \\ \text { CD8+-T cell } & \uparrow \\ \text { Hapten-specific IFN- } \gamma \text {-producing CD8+-T cell } & \downarrow \\ \text { CD57+-T cells } & \uparrow\end{array}$

Toll-like Receptor Stimulation

Activate TLR-2

$\uparrow$

Activate TLR-9

$\uparrow$

TLR-3 and TLR-4

Abbreviations: Lctbs = Lactobacillus; Bfdbm = Bifidobacterium; LGG = Lactobacillus rhamnosus GG; LL= Lactococcus lactis; $\uparrow=$ increase in symptoms or negative effect; $\downarrow=$ decrease in symptoms or positive effect; $\leftrightarrow=$ No change in symptoms or no effect.

\subsubsection{Immunomodulation: Th1/Th2 Balance, Serum Cytokines and IgE Production}

In addition to maturing gut barrier, certain strains of Lactobacilli and Bifidobacteria modulate the production of cytokines by monocytes and lymphocytes, and may divert the immune system in a regulatory or tolerant mode $[48,49]$. Although the cytokine stimulation profiles of different probiotic strains vary, the strains isolated from healthy infants mainly stimulate non-inflammatory cytokines [50]. For instance, Lactobacillus reuteri in- duced proinflammatory and Th1 cytokines; and Bifidobacterium bifidum/infantis and Lactobacillus lactis reduced Th2 cytokines [51]. Nonetheless, there are still some studies showing no significant effects of probiotics on either Th1/Th2 cell responses to allergens.

Several studies have shown the immunomodulatory effects of probiotic bacteria. In one study, Bifidobacterium bifidum/infantis and Lactobacillus lactis reduced Th2 cytokines and acted as potent inducers of IL-10 production in different peripheral blood mononuclear cell 
cultures [52]. In another study, 8 common Lactobacillus strains were studied with respect to induction of cytokines by the murine gut mucosa in response to a parenterally administered antigen. Lactobacillus reuteri induced proinflammatory and Th1 cytokines; however, Lactobacillus casei tended to induce IL-10/IL-4 [50]. Yet on the contrary, in some children receiving probiotics, reduced IL-10 responsiveness to house dust mites allergens was observed [53]. In a study, the effects of feeding Lactobacillus F19 were evaluated during weaning on the incidence of eczema and Th1/Th2 balance. At 13 months of age, the higher Th1/Th2 ratio and reduced eczema incidence in the probiotic compared with the placebo group suggests enhancing effects of Lactobacillus F19 on the $T$ cell-mediated immune response [54].

In a mouse model, effect of oral probiotics administration, including Bifidobacterium lactis/bifidum and Lactobacillus acidophilus, on mice with ovalbumin (OVA)induced food allergy was studied. The mice treated with probiotics suppressed production of the OVA-specific $\operatorname{IgE}, \operatorname{IgG} 1$, and $\operatorname{IgA}$. Additionally, the level of IL-4 was significantly lower, and the levels of INF- $\gamma$ and IL-10 were significantly higher in the mice treated with probiotics than that in the nontreated mice [55]. Another murine model showed that oral administration of an immunostimulatory DNA sequence from Bifidobacterium longum suppressed Th2 immune responses in mice and inhibited IgE production in vitro [48]. Similarly, Lactobacillus acidophilus suppressed the development of atopic dermatitis-like skin lesions in sensitized NC/Nga mice via decreasing serum total IgE level [56]. A final study showed that the administration of either Bifidobacterium lactis or LGG suppressed antigen-specific IgE production too [57].

Atopic dermatitis-like skin lesions were induced by repeated challenges with mostly picrylchloride in the Th2-skewed NC/Nga mouse strain. Oral administration of lactic acid bacteria (Lactobacillus delbrueckii subsp. lactis R-037) isolated from traditional South Asian fermented milk "dahi" inhibits the development of atopic dermatitis thru exhibiting IL-12 as a potent Th1 inducer [58]. Also, the anti-allergic effects of one strain (T120) of lactic acid bacteria isolated from Mongolian fermented milk using $\mathrm{AD}$ model mice (NC/Nga mice) were investigated. Strain T120 has already been identified as Enterococcus faecium and suppressed total IgE production and induced IL-12 and IFN- $\gamma$ production by splenocytes of NC/Nga mice. Further, this strain enhanced the production of IL-10 by splenocytes and activation of Tregs by strain T120 may inhibit atopic disease [59]. In another study, Lactobacillus plantarum strains from Kimchi were demonstrated to inhibit atopic dermatitis (house-dust mite-induced dermatitis) in NC/Nga mouse. Lactobacilli isolated from Kimchi inhibit atopic dermatitis, probably by altering the balance of $\mathrm{Th} 1 / \mathrm{Th} 2$ ratio or inducing IL10 production [60]. A new synbiotic, Lactobacillus casei subsp. casei together with dextran, reduces the development of atopic dermatitis-like skin lesions in $\mathrm{NC} / \mathrm{Nga}$ mice. This synbiotic combination significantly decreased clinical skin severity scores induced by picryl chloride and total IgE levels in sera of NC/Nga mice [61]. Also, supplementation with KW3110 strain of lactic acid bacteria significantly attenuated the onset and exacerbation of atopic dermatitis-like skin lesions, accompanied by lower plasma IgE levels thru its effects on IL-12 and IL-4 production in vitro [62]. Oral administration of Lactobacillus brevis significantly inhibited $\operatorname{IgE}$ production and ear swelling, and suppressed the development of dermatitis in a dose-dependent manner in atopic dermatitis model of NC/Nga mice. Cytokines e.g. IL-10 and TGF- $\beta$ production from Peyer's patch cells significantly increased in the treatment group [63]. Consistently, oral supplementation with Lactobacillus rhamnosus in a study by Tanaka et $a l$. has been demonstrated to prevent development of atopic dermatitis in NC/NgaTnd mice possibly by modulating local production of IFN- $\gamma$ and plasma total IgE in skin biopsies [64].

Probiotic supplementation decreased the severity of allergic skin responses in allergen-sensitized pigs with a corresponding increase in IFN- $\gamma$ expression [65]. Consistently, Pohjavuori et al. were able to demonstrate an increase of IFN- $\gamma$ production in peripheral blood mononuclear cells in infants with atopic dermatitis treated with LGG [66]. Additionally, the improvement in atopic dermatitis severity of very young children with probiotic treatment was detected to be associated with increases in IFN- $\gamma$ responses [67]. However, Rosenfeldt et al. demonstrated no significant changes in serum cytokines during 6 weeks of probiotic treatment [68]. Brouwer et al. also showed no statistically significant effects of probiotic supplementation on cytokine production as well [69]. As a result, it seems that changes in cytokine profile induced by probiotics may be probiotic strain- or site-specific and dependent on the experimental system used.

\subsubsection{Systemic Anti-Inflammatory Effects}

The anti-inflammatory effect of probiotics has been attributed to increased production of IL-10 by immune cells in the lamina propria, Peyer's patches and the spleen of treated animals. Moreover, a decrease in the secretion of pro-inflammatory cytokines, IFN- $\gamma$, TNF- $\alpha$ and IL-12 has been demonstrated [39,47,50,52]. Oral administration of LGG resulted in elevated IL-10 concentrations in atopic children, indicating that specific probiotics may have anti-inflammatory effects in vivo and possible enhancing regulatory or tolerance-inducing 
mechanisms as well [70]. A review of the evidence from randomized controlled trials by Betsi et al. about probiotics for the treatment or prevention of atopic dermatitis: the results of 13 relevant randomized controlled trials were reviewed: 10 of which evaluated probiotics as treatment and 3 for prevention of atopic dermatitis. In four of these six randomized controlled trials, clinical improvement was associated with a change in some inflammatory markers [71].

A study by Woo et al. evaluated the effect of Lactobacillus sakei supplementation in children with atopic eczema-dermatitis syndrome. In this study, compared with placebo, probiotic administration was associated with lower pretreatment-adjusted serum levels of chemokines such as CCL17 and CCL27, which were significantly correlated with SCORAD total score [72]. Primary administration of Lactobacillus johnsonii in weaning period suppressed the elevation of proinflammatory cytokines and CD86 gene expressions in skin lesions of NC/Nga model mice. The suppression of proinflammatory cytokines e.g. IL-8/-12/-23 and CD86 expression by Lactobacillus johnsonii may significantly contribute to the inhibitory effect on the skin lesion like atopic dermatitis [73].

Nevertheless, another randomized, double-blind, placebo-controlled study conducted by Brouwer et al. showed no statistically significant effects of probiotic supplementation on inflammatory parameters [67]. Interestingly; probiotic-induced chronic low-grade inflammation characterized by elevation of CRP, $\operatorname{IgE}, \operatorname{IgA}$, and IL-10 was shown in some studies, the changes typically observed in helminth infection-associated induction of regulatory mechanisms. The association of increased CRP with a decreased risk of eczema at 2 years of age in allergy-prone children supports the view that chronic, low-grade inflammation protects from eczema. The findings emphasize the role of chronic microbial exposure as an immunomodulator protecting from allergy [74].

\subsubsection{Suppression of Th17 Cells (Reducing Proinflammatory Cytokines through Th17 Cells)}

T-helper 17 (Th17) cells, a subset of CD4+ T cells have been implicated as having an important role in the development of several allergic disorders, but the relationship between oral administration of probiotics and Th17 development has not been well studied. Th17 cells have been also shown as pathogenic cells in some autoimmune diseases such as experimental autoimmune enmcephalomyelitis and arthritis [75]. Some probiotics have been reported to reduce proinflammatory cytokines through Th17 cells. Suppression of this newly discovered subset of $T$ cells by probiotics might explain effects observed in different experimental models that all involve inflammatory responses, i.e. colitis. For instance, Lactobacillus casei suppressed inflammation in experimental arthritis reducing proinflammatory cytokines released from Th17 cells [76]. Also, in a study administration of a probiotics mixture (Lactobacillus acidophilus, Lactobacillus casei, Lactobacillus reuteri, Bifidobacterium bifidium, and Streptococcus thermophilus) induced both T-cell and B-cell hyporesponsiveness and down-regulated Th1, Th2, and Th17 cytokines [77].

\subsubsection{Development of Tolerogenic Dendritic Cells}

Selected species of the Bifidobacterium genus were demonstrated to prime in vitro cultured neonatal dendritic cells to polarize $\mathrm{T}$ cell responses and may therefore be used as candidates in primary prevention of allergic diseases. Bifidobacterium bifidum was found to be most potent polarizer in vitro-cultured dendritic cells to drive Th1-cell responses involving increased IFN- $\gamma$ producing $\mathrm{T}$ cells concomitant with reduction of IL-4-producing T-cells [78]. In addition, T-cells stimulated by Bifidobacterium bifidum matured dendritic cells as producers of more IL-10 [79]. Moreover, Lactobacillus rhamnosus, member of another genus of probiotic bacteria, modulates dendritic cell function to induce a novel form of T-cell hyporesponsiveness [49]. Lactobacillus reuteri/ casei have been also shown to prime monocyte-derived dendritic cells through the C-type lectin dendritic cellspecific intercellular adhesion molecule 3-grabbing nonintegrin (dendritic cell-SIGN) to drive the development of Tregs [80]. These Treg cells produce increased levels of IL-10 and are capable of inhibiting the proliferation of bystander $\mathrm{T}$ cells. This study suggests that the targeting of dendritic cell-SIGN by certain probiotic bacteria might explain their beneficial effect in the treatment of a number of inflammatory diseases, including atopic and autoimmune diseases.

\subsubsection{Immunoregulation by T Regulatory (Treg) Cells}

As mentioned earlier, Lactobacillus reuteri/casei have been also shown to prime monocyte-derived dendritic cells through the dendritic cell-SIGN to drive the development of Tregs [80]. And the probiotic combinations are alleged to cause a paradoxic Th2 stimulation and to induce chronic low-grade inflammation, practically the same as in chronic and balanced helminth infection, which is associated with activation of Treg cells suppressing allergic inflammation [74]. CD4+/25+-Tregs have shown to be pivotal players in the maintenance of immune tolerance. Their role in the prevention of autoimmunity in animal models and evidence for disturbed or dysfunction of Tregs have also been observed in patients with different autoimmune diseases, including multiple 
sclerosis [21].

Recent studies provided evidence that one effect of probiotics may involve induction of differentiation of IL-10-dependent, TGF- $\beta$-bearing Tregs $[21,81]$. They also can suppress immune responses distinct from responses against the antigen in question, here antigens expressed by infectious agents (a phenomenon called bystander suppression). In a food allergy mouse model, oral administration of Bifidobacterium bifidum and Lactobacillus acidophilus suppressed OVA-specific IgE production, which was caused by inducing Treg-associated TGF- $\beta$ production [55]. Another study demonstrated that neonatal application of probiotic bacteria inhibits subsequent allergic sensitization and airway disease in a murine model of asthma by induction of Treg cells and TGF- $\beta$ production [82]. In another study, the regulatory cytokine and cell response to probiotic (VSL\#3) administration in the context of the Th1-mediated colitis of $\mathrm{SJL} / \mathrm{J}$ mice was analyzed. Probiotic VSL\#3 administration during a remission period ameliorated the severity of recurrent colitis by inducing an immunoregulatory response involving an early increase in the production of IL-10 and TGF- $\beta$-bearing T-regs [83].

Generation of CD4+/ Foxp3+-Treg cells by probiotics administration suppresses autoimmune and allergic disorders. Recently, two studies reported that oral administration of a certain probiotic strain e.g. Lactobacillus casei could increase Foxp3+-Tregs [84,85]. It is known that the lower percentage of epidermal or dermal Foxp3+ cells in eczematous dermatitis might contribute to their pathogenesis [85]. The strain T120 of lactic acid bacteria was shown to be able to inhibit atopic disease in NC/Nga mice thru enhanced production of IL-10 by splenocytes and activation of Teg cells [84]. In a recent study, a mixture of probiotics (Lactobacillus acidophilus, Lactobacillus casei, Lactobacillus reuteri, Bifidobacterium bifidium, and Streptococcus thermophilus) was identified that up-regulates CD4+/Foxp3+-Treg cells. Administration of the probiotics mixture induced both T-cell and B-cell hyporesponsiveness and down-regulated Th1, Th2, and Th17 cytokines. It also induced generation of $\mathrm{CD} 4+/$ Foxp3+-Tregs from the CD4+/25-population and increased the suppressor activity of naturally occurring CD4+/25+-Tregs. Conversion of $\mathrm{T}$ cells into Foxp3+ Tregs is directly mediated by regulatory dendritic cells that express high levels of IL-10 and TGF- $\beta$ [86]. However, another study showed that Foxp3 mRNA expression at 6 months of age is higher in infants having atopic dermatitis, but it is not affected by giving probiotics from birth [87]. In sensitized BALB/c mice, skin inflammation was induced by topical allergen application. E. coli Nissle 1917 was administered orally in a preventive manner and it improved allergen-induced dermatitis dosedependently. E. coli Nissle altered the local allergen- induced immune response by Foxp3+-cell increase and by favoring immunoregulatory cytokine patterns [88].

\subsubsection{Changes in Lymphocyte Subpopulations}

Several studies reveal that the probiotics differently modulate peripheral blood immune parameters in healthy subjects and patients with atopic diseases. Gerasimov et $a l$. conducted a study to assess the clinical efficacy and impact of Lactobacillus acidophilus plus Bifidobacterium lactis with fructo-oligosaccharide on peripheral blood lymphocyte subsets in preschool children with moderate-to-severe atopic dermatitis. The percentage of $\mathrm{CD} 4$, and the percentage/absolute count of CD25 decreased, and the percentage/absolute count of CD8 increased in the probiotic group at week 8 , compared with placebo. They found a significant correlation between CD4 percentage, CD25 percentage, CD25 absolute count, and SCORAD values in the probiotic group at week 8 . The administration of a probiotic mixture and fructooligosaccharide was correlated with significant clinical improvement in children with atopic dermatitis, with corresponding lymphocyte subpopulation changes in peripheral blood [89].

Also in other mice studies, contact hypersensitivity to the hapten 2,4-dinitrofluorobenzene, a model of allergic contact dermatitis mediated by CD8+-cytotoxic $\mathrm{T}$ lymphocytes and controlled by CD4+-Treg cells was studied. Daily oral administration of fermented milk containing Lactobacillus casei or Lactobacillus casei alone decreased skin inflammation by inhibiting the priming/ expansion of hapten-specific IFN- $\gamma$-producing CD8+effector $\mathrm{T}$ cells. This study provides the first evidence that oral administration of Lactobacillus casei can reduce antigen-specific skin inflammation by controlling the size of the CD8+-effector pool [90].

However, in some studies major lymphocyte subsets were not affected by the probiotic intervention. The purpose of a study by Roessler et al. was to elucidate the influence of a probiotic drink containing a combination of the probiotics Lactobacillus paracasei, Lactobacillus acidophilus and Bifidobacterium animalis in healthy volunteers and in patients with atopic dermatitis on clinical and immunological parameters and their detection in feces. This double-blind, randomized cross-over study was conducted in 15 healthy adults and 15 patients with atopic dermatitis. In atopic dermatitis patients, the SCORAD tended to decrease by $16 \%$. The expression of $\mathrm{CD}^{+} / 25+-\mathrm{T}$ cells was similar in healthy subjects and atopic dermatitis patients, whereas $\mathrm{CD} 4+/ 54+$-cells decreased significantly in patients with atopic dermatitis and remained uninfluenced in healthy subjects. However, $\mathrm{CD} 57^{+}-\mathrm{T}$ cells increased significantly in healthy subjects after probiotic intake and was not changed in patients [91]. 


\subsubsection{Systemic Toll-Like Receptor (TLR) Stimulation via Non-Antigenic Ligands}

A number of experiments indicate that infectious agents can promote protection from atopic and autoimmune diseases through mechanisms independent of their constitutive antigens, leading to stimulation of non-antigen specific receptors such as TLRs. A family of pattern recognition receptors such as TLRs on gut lymphoid and epithelial cells mediates innate immune responses to bacterial molecular patterns and, thereby, orchestrates acquired immunity. The transient protection offered by probiotics against IgE-associated allergic diseases is based on stimulation of TLRs, which produce mediators such as IL-6; these further induce IgA differentiation from naive $B$ cells. Both these events were shown to occur after probiotic administration to infants with eczema, as well as in infants who showed increased levels of serum CRP, IL-10, and IgE at the age of 6 months [74]. Similarly, an observation made for TLR-2/-3/-4/-7 and -9 that TLR stimulation could prevent the onset of type 1 diabetes in non-obese diabetes mice $[92,93]$.

As mentioned, TLR stimulation was also thought to happen after probiotic administration in infants with eczema who showed increased levels of serum CRP, IL-10, and IgE. This probiotic-induced low-grade inflammation was characterized by elevation of CRP, $\operatorname{IgE}$, IgA, and IL-10, the changes typically observed in helminth infection-associated induction of regulatory mechanisms. Moreover, the association of increased CRP with a decreased risk of eczema at 2 years of age in allergy-prone children supports the view that chronic, low-grade inflammation protects from eczema. The findings emphasize the role of chronic microbial exposure as an immunomodulator protecting from allergy thru activation of Treg cells by TLR stimulation [74]. Consistently, lactic acid bacteria species such as Bifidobacterium bifidum/infantis and Lactobacillus salivarius were shown to be capable of activating TLR-2 [94]. Oral administration of Lactobacillus reuteri attenuated major characteristics of an asthmatic response, including airway eosinophilia, local cytokine responses, and hyperresponsiveness to methacholine. This effect of Lactobacillus reuteri on the allergic airway response was found to be dependent on TLR-9 [95]. A systematic study was performed by Aumeunier et al. on the disease-modifying effects of a set of natural or synthetic TLR agonists using two experimental non-obese diabetes mouse models, OVAinduced asthma and spontaneous autoimmune type 1 diabetes. In these models, probiotics which stimulate TLRs also were shown to protect from these two diseases. These results strongly indicate that the TLRmediated effects involve immunoregulatory cytokines such as IL-10 and TGF- $\beta$ and different subsets of Treg cells, notably CD4+/CD25+/FoxP3+-T cells for TLR-4 agonists and NKT cells for TLR-3 agonists [96].

\section{CONCLUSION}

In summary, local influences of probiotics potentially include reduction of gut permeability and systemic penetration of antigens, increased local IgA production, and alteration of local inflammation or tolerance induction. Some possible systemic effects consist of anti-inflammatory effects mediated by Th17 cells and TLRs, Th1 skewing of responses to allergens, activation of tolerogenic dendritic cells, in addition to Treg cell production.

\section{REFERENCES}

[1] Björkstén, B., Sepp, E., Julge, K., et al. (2001) Allergy development and the intestinal microflora during the first year of life. Journal of Allergy and Clinical Immunology, 108, 516-520. doi:10.1067/mai.2001.118130

[2] Das, R.R. (2011) Cesarean delivery, antibiotic exposure, and probiotics: Relationship with childhood asthma. Journal of Allergy and Clinical Immunology, 128, 1133-1134. doi:10.1016/j.jaci.2011.07.043

[3] Newburg, D.S. (2000) Oligosaccharides in human milk and bacterial colonization. Journal of Pediatric Gastroenterology and Nutrition, 30, S8-S17.

[4] Matsuki, T., Watanabe, K., Tanaka, R., et al. (1999) Distribution of bifidobacterial species in human intestinal microflora examined with $16 \mathrm{~S}$ rRNA-gene-targeted species-specific primers. Applied and Environmental Microbiology, 65, 4506-4512.

[5] Harmsen, H.J., Wildeboer-Veloo, A.C., Raangs, G.C., et al. (2000) Analysis of intestinal flora development in breast-fed and formula-fed infants by using molecular identification and detection methods. Journal of Pediatric Gastroenterology and Nutrition, 30, 61-67. doi:10.1097/00005176-200001000-00019

[6] Yoshioka, H., Iseki, K. and Fujita, K. (1983) Development and differences of intestinal flora in the neonatal period in breast-fed and bottle-fed infants. Pediatrics, 72, 317-321.

[7] Kalliomaki, M., Kirjavainen, P., Eerola, E., et al. (2001) Distinct patterns of neonatal gut microflora in infants in whom atopy was and was not developing. Journal of $\mathrm{Al}$ lergy and Clinical Immunology, 107, 129-134. doi:10.1067/mai.2001.111237

[8] Kirjavainen, P.V., Arvola, T., Salminen, S.J. and Isolauri, E. (2002) Aberrant composition of gut microbiota of allergic infants: a target of bifidobacterial therapy at weaning? Gut, 51, 51-55. doi:10.1136/gut.51.1.51

[9] Sepp, E., Julge, K., Mikelsaar, M. and Björkstén, B. (2005) Intestinal microbiota and immunoglobulin $\mathrm{E}$ responses in 5-year-old Estonian children. Clinical \& Experimental Allergy, 35, 1141-1146. doi:10.1111/j.1365-2222.2005.02315.x

[10] Özdemir, Ö. (2009) Gut flora development in infancy and 
its effect on immune system. Journal of Pediatric Infection, 3, 202-203.

[11] Metchnikoff, E. (1907) The prolongation of life: Optimistic studies. G. P. Putnam \& Sons, London.

[12] Food and Agriculture Organization, World Health Organization (2001) Report of joint FAO/WHO expert consultation on evaluation of health and nutritional properties of probiotics in food including powder milk with live lactic acid bacteria. FAO/WHO Report, World Health Organization, 10-11.

[13] Özdemir, Ö. (2009) Any benefits of probiotics in allergic disorders? Allergy and Asthma Proceedings, 31, 103-111. doi:10.2500/aap.2010.31.3313

[14] Cabana, M.D., McKean, M., Wong, A.R., et al. (2007) Examining the hygiene hypothesis: The Trial of infant probiotic supplementation. Paediatric and Perinatal Epidemiology, 21, 23-28. doi:10.1111/j.1365-3016.2007.00881.x

[15] Ljungberg, M., Korpela, R., Ilonen, J., et al. (2006) Probiotics for the prevention of beta cell autoimmunity in children at genetic risk of type 1 diabetes: The PRODIA study. Annals of the New York Academy of Sciences, 1079, 360-364. doi:10.1196/annals.1375.055

[16] Vaarala, O, Atkinson, M.A. and Neu, J. (2008) The "Perfect Storm" for type 1 diabetes: The complex interplay between intestinal microbiota, gut permeability, and mucosal immunity. Diabetes, 57, 2555-2562. doi:10.2337/db08-0331

[17] Bach, J.F. (2002) The effect of infections on susceptibility to autoimmune and allergic diseases. The New England Journal of Medicine, 347, 911-920. doi:10.1056/NEJMra020100

[18] Petrovsky, N. (2010) Immunomodulation with microbial vaccines to prevent type 1 diabetes mellitus. Nature Reviews Endocrinology, 6, 131-138. doi:10.1038/nrendo.2009.273

[19] Boerner, B.P. and Sarvetnick, N.E. (2011) Type 1 diabetes: role of intestinal microbiome in humans and mice. Annals of the New York Academy of Sciences, 1243, 103-118. doi:10.1111/j.1749-6632.2011.06340.x

[20] Prescott, S.L., Macaubas, C., Holt, B.J., et al. (1998) Transplacental priming of the human immune system to environmental allergens: universal skewing of initial $\mathrm{T}$ cell responses toward the Th2 cytokine profile. Journal of Immunology, 160, 4730-4737.

[21] Schwartz, R.H. (2005) Natural regulatory T cells and selftolerance. Nature Immunology, 6, 327-330. doi:10.1038/ni1184

[22] Billmann-Born, S., Till, A., Arlt, A., et al. (2011) Genomewide expression profiling identifies an impairment of negative feedback signals in the Crohn's disease-associated NOD2 variant L1007fsinsC. Journal of Immunology, 186, 4027-4038. doi:10.4049/jimmunol.1000085

[23] Walsh, K.P., Brady, M.T., Finlay, C.M., et al. (2009) Infection with a helminth parasite attenuates autoimmunity through TGF-beta-mediated suppression of Th17 and Th1 responses. Journal of Immunology, 183, 1577-1586. doi:10.4049/jimmunol.0803803

[24] Sgouroudis, E., Kornete, M. and Piccirillo, C.A. (2011) IL-2 production by dendritic cells promotes Foxp3(+) regulatory T-cell expansion in autoimmune-resistant NOD congenic mice. Autoimmunity, 44, 406-414. doi:10.3109/08916934.2010.536795

[25] Okada, H., Kuhn, C., Feillet, H. and Bach, J.F. (2010) The "hygiene hypothesis" for autoimmune and allergic diseases: An update. Clinical \& Experimental Immunology, 160, 1-9. doi:10.1111/j.1365-2249.2010.04139.x

[26] Tlaskalová-Hogenová, H., Stepánková, R., Hudcovic, T., et al. (2004) Commensal bacteria (normal microflora), mucosal immunity and chronic inflammatory and autoimmune diseases. Immunology Letters, 93, 97-108. doi:10.1016/j.imlet.2004.02.005

[27] Matsuzaki, T., Takagi, A., Ikemura, H., et al. (2007) Intestinal microflora: probiotics and autoimmunity. Journal of Nutrition, 137, 798S-802S.

[28] Kubota, A., He, F., Kawase, M., et al. (2011) Diversity of intestinal bifidobacteria in patients with Japanese cedar pollinosis and possible influence of probiotic intervention. Current Microbiology, 62, 71-77. doi:10.1007/s00284-010-9667-5

[29] Canche-Pool, E.B., Cortez-Gómez, R., Flores-Mejía, R., et al. (2008) Probiotics and autoimmunity: An evolutionary perspective. Medical Hypotheses, 70, 657-660. doi:10.1016/j.mehy.2007.07.008

[30] de Kort, S., Keszthelyi, D. and Masclee, A.A. (2011) Leaky gut and diabetes mellitus: what is the link? Obesity Reviews, 12, 449-458. doi:10.1111/j.1467-789X.2010.00845.x

[31] Kim, N.Y. and Ji, G.E. (2012) Effects of probiotics on the prevention of atopic dermatitis. Korean Journal of Pediatrics, 55, 193-201. doi:10.3345/kjp.2012.55.6.193

[32] Özdemir, Ö. (2010) Various effects of different probiotic strains in allergic disorders: An update from laboratory and clinical data. Clinical \& Experimental Immunology, 160, 295-304. doi:10.1111/j.1365-2249.2010.04109.x

[33] Majamaa, H. and Isolauri, E. (1997) Probiotics. A novel approach in the management of food allergy. Journal of Allergy and Clinical Immunology, 99, 179-185. doi:10.1016/S0091-6749(97)70093-9

[34] Kalliomäki, M., Salminen, S., Poussa, T. and Isolauri, E. (2007) Probiotics during the first 7 years of life: A cumulative risk reduction of eczema in a randomized, placebocontrolled trial. Journal of Allergy and Clinical Immunology, 119, 1019-1021. doi:10.1016/j.jaci.2006.12.608

[35] Singh, B. and Rabinovitch, A. (1993) Influence of microbial agents on the development and prevention of autoimmune diabetes. Autoimmunity, 15, 209-213. doi:10.3109/08916939309019929

[36] Brugman, S., Klatter, F.A., Visser, J.T., et al. (2006) Antibiotic treatment partially protects against type 1 diabetes in the bio-breeding diabetes-prone rat. Is the gut flora involved in the development of type 1diabetes? Diabetologia, 49, 2105-2108. doi:10.1007/s00125-006-0334-0

[37] Sudo, N., Sawamura, S., Tanaka, K., et al. (1997) The requirement of intestinal bacterial flora for the develop- 
ment of an IgE production system fully susceptible to oral tolerance induction. The Journal of Immunology, 159, 1739-1745.

[38] Miele, E., Pascarella, F., Giannetti, E., et al. (2009) Effect of a probiotic preparation (VSL\#3) on induction and maintenance of remission in children with ulcerative colitis. The American Journal of Gastroenterology, 104, 437443. doi:10.1038/ajg.2008.118

[39] Dotan, I. and Rachmilewitz, D. (2005) Probiotics in inflammatory bowel disease: Possible mechanisms of action. Current Opinion in Gastroenterology, 21, 426-430.

[40] Sawada, J., Morita, H., Tanaka, A., et al. (2007) Ingestion of heat-treated Lactobacillus rhamnosus GG prevents development of atopic dermatitis in NC/Nga mice. Clinical \& Experimental Allergy, 37, 296-303. doi:10.1111/j.1365-2222.2006.02645.x

[41] Cebra, J.J. (1999) Influences of microbiota on intestinal immune system development. The American Journal of Clinical Nutrition, 69, 1046S-1051S.

[42] Sistek, D., Kelly, R., Wickens, K., et al. (2006) Is the effect of probiotics on atopic dermatitis confined to food sensitized children? Clinical \& Experimental Allergy, 36, 629-633. doi:10.1111/j.1365-2222.2006.02485.x

[43] Pessi, T., Isolauri, E., Sutas, Y., Kankaanranta, H., Moilanen, E. and Hurme, M. (2001) Suppression of T cell activation by Lactobacillus rhamnosus GG-degraded bovine casein. Immunopharmacology, 1, 211-218. doi:10.1016/S1567-5769(00)00018-7

[44] Kaila, M., Isolauri, E., Soppi, E., et al. (1992) Enhancement of the circulating antibody secreting cell response in human diarrhea by a human Lactobacillus strain. Pediatric Research, 32, 141-144. doi:10.1203/00006450-199208000-00002

[45] Isolauri, E., Sütas, Y., Kankaanpää, P., et al. (2001) Probiotics: Effects on immunity. The American Journal of Clinical Nutrition, 73, 444S-450S.

[46] Inoue, R., Nishio, A., Fukushima, Y. and Ushida, K. (2007) Oral treatment with probiotic Lactobacillus johnsonii NCC533 (La1) for a specific part of the weaning period prevents the development of atopic dermatitis induced after maturation in model mice, NC/Nga. British Journal of Dermatology, 156, 499-509. doi:10.1111/j.1365-2133.2006.07695.x

[47] Salminen, S.J., Gueimonde, M. and Isolauri, E. (2005) Probiotics that modify disease risk. Journal of Nutrition, 135, 1294-1298.

[48] Takahashi, N., Kitazawa, H., Iwabuchi, N., et al. (2006) Immunostimulatory oligodeoxynucleotide from Bifidobacterium longum suppresses Th2 immune responses in a murine model. Clinical \& Experimental Immunology, 145, 130-138. doi:10.1111/j.1365-2249.2006.03111.x

[49] Braat, H., Van Den Brande, J., Van Tol, E., et al. (2004) Lactobacillus rhamnosus induces peripheral hyporesponsiveness in stimulated $\mathrm{CD}^{+} \mathrm{T}$ cells via modulation of dendritic cell function. The American Journal of Clinical Nutrition, 80, 1618-1625.

[50] Maassen, C.B., Van Holten-Neelen, C., Balk, F., et al. (2000) Strain-dependent induction of cytokine profiles in the gut by orally administered Lactobacillus strains. Vaccine, 18, 2613-2623.

doi:10.1016/S0264-410X(99)00378-3

[51] Shida, K., Nanno, M., Nagata, S. (2011) Flexible cytokine production by macrophages and $\mathrm{T}$ cells in response to probiotic bacteria: A possible mechanism by which probiotics exert multifunctional immune regulatory activities. Gut Microbes, 2,109-114. doi:10.4161/gmic.2.2.15661

[52] Niers, L.E., Timmerman, H.M., Rijkers, G.T., et al. (2005) Identification of strong interleukin-10 inducing lactic acid bacteria which downregulate $\mathrm{T}$ helper type 2 cytokines. Clinical \& Experimental Allergy, 35, 1481-1489. doi:10.1111/j.1365-2222.2005.02375.x

[53] Kruisselbrink, A., Heijne Den Bak-Glashouwer, M.J., Havenith, C.E., et al. (2001) Recombinant Lactobacillus plantarum inhibits house dust mite-specific T-cell responses. Clinical \& Experimental Immunology, 126, 2-8. doi:10.1046/j.1365-2249.2001.01642.x

[54] West, C.E., Hammarström, M.L. and Hernell, O. (2009) Probiotics during weaning reduce the incidence of eczema. Pediatric Allergy and Immunology, 20, 430-437. doi:10.1111/j.1399-3038.2009.00745.x

[55] Kim, J.Y., Choi, Y.O. and Ji, G.E. (2008) Effect of oral probiotics (Bifidobacterium lactis AD011 and Lactobacillus acidophilus AD031) administration on ovalbumin-induced food allergy mouse model. Journal of Microbiology and Biotechnology, 18, 1393-1400.

[56] Sunada, Y., Nakamura, S. and Kamei, C. (2008) Effect of Lactobacillus acidophilus strain L-55 on the development of atopic dermatitis-like skin lesions in NC/Nga mice. International Immunopharmacology, 8, 1761-1766. doi:10.1016/j.intimp.2008.08.011

[57] Shida, K., Makino, K. and Morishita, A. (1998) Lactobacillus casei inhibits antigen induced IgE secretion through regulation of cytokine production in murine splenocyte cultures. International Archives of Allergy and Immunology, 115, 278-287. doi:10.1159/000069458

[58] Watanabe, T., Hamada, K., Tategaki, A., et al. (2009) Oral administration of lactic acid bacteria isolated from tradi- tional South Asian fermented milk 'dahi' inhibits the de- velopment of atopic dermatitis in NC/Nga mice. Journal of Nutritional Science and Vitaminology, 55, 271-278. doi: $10.3177 /$ jnsv. 55.271

[59] Hayashi, A., Kimura, M., Nakamura, Y. and Yasui, H. (2009) Anti-atopic dermatitis effects and the mechanism of lactic acid bacteria isolated from Mongolian fermented milk. Journal of Dairy Research, 76, 158-164. doi: $10.1017 / \mathrm{S} 0022029908003725$

[60] Won, T.J., Kim, B, Lim, Y.T., et al. (2011) Oral administration of Lactobacillus strains from Kimchi inhibits atopic dermatitis in $\mathrm{NC} / \mathrm{Nga}$ mice. Journal of Applied Microbiology, 110, 1195-1202. doi:10.1111/j.1365-2672.2011.04981.x

[61] Ogawa, T., Hashikawa, S., Asai, Y., et al. (2006) A new synbiotic, Lactobacillus casei subsp. casei together with dextran, reduces murine and human allergic reaction. 
FEMS Immunology and Medical Microbiology, 46, 400409. doi:10.1111/j.1574-695X.2006.00046.x

[62] Wakabayashi, H., Nariai, C., Takemura, F., et al. (2008) Dietary supplementation with lactic acid bacteria atenuates the development of atopic-dermatitis-like skin lesions in NC/Nga mice in a strain-dependent manner. International Archives of Allergy and Immunology, 145, 141-151. doi:10.1159/000108139

[63] Segawa, S., Hayashi, A., Nakakita, Y., et al. (2008) Oral administration of heat-killed Lactobacillus brevis SBC8803 ameliorates the development of dermatitis and inhibits immunoglobulin E production in atopic dermatitis model NC/Nga mice. Biological \& Pharmaceutical Bulletin, 31, 884-889. doi:10.1248/bpb.31.884

[64] Tanaka, A., Jung, K., Benyacoub, J., et al. (2009) Oral supplementation with Lactobacillus rhamnosus CGMCC 1.3724 prevents development of atopic dermatitis in NC/NgaTnd mice possibly by modulating local production of IFN-gamma. Experimental Dermatology, 18, 1022-1027. doi:10.1111/j.1600-0625.2009.00895.x

[65] Thomas, D.J., Husmann, R.J., Villamar, M., et al. (2011) Lactobacillus rhamnosus HN001 attenuates allergy development in a pig model. PLOS ONE, 6, e16577. doi:10.1371/journal.pone.0016577

[66] Pohjavuori E, Viljanen M, Korpela R, et al. (2004) Lactobacillus GG effect in increasing IFN-gamma production in infants with cow's milk allergy. Journal of Allergy and Clinical Immunology, 114, 131-136. doi:10.1016/j.jaci.2004.03.036

[67] Prescott, S.L., Dunstan, J.A., Hale, J., et al. (2005) Clinical effects of probiotics are associated with increased interferon-gamma responses in very young children with atopic dermatitis. Clinical \& Experimental Allergy, 35, 1557-1564. doi:10.1111/j.1365-2222.2005.02376.x

[68] Rosenfeldt, V., Benfeldt, E., Nielsen, S.D., et al. (2003) Effect of probiotic Lactobacillus strains in children with atopic dermatitis. Journal of Allergy and Clinical Immunology, 111, 389-395. doi:10.1067/mai.2003.389

[69] Brouwer, M.L., Wolt-Plompen, S.A., Dubois, A.E., et al. (2006) No effects of probiotics on atopic dermatitis in infancy: A randomized placebo-controlled trial. Clinical \& Experimental Allergy, 36, 899-906. doi:10.1111/j.1365-2222.2006.02513.x

[70] Pessi, T., Sütas, Y., Hurme, M. and Isolauri, E. (2000) Interleukin-10 generation in atopic children following oral Lactobacillus rhamnosus GG. Clinical \& Experimental Allergy, 30, 1804-1808. doi:10.1046/j.1365-2222.2000.00948.x

[71] Betsi, G.I., Papadavid, E. and Falagas, M.E. (2008) Probiotics for the treatment or prevention of atopic dermatitis: A review of the evidence from randomized controlled trials. American Journal of Clinical Dermatology, 9, 93-103. doi:10.2165/00128071-200809020-00002

[72] Woo, S.I., Kim, J.Y., Lee, Y.J., et al. (2010) Effect of Lactobacillus sakei supplementation in children with atopic eczema-dermatitis syndrome. Annals of Allergy, Asthma \& Immunology, 104, 343-348. doi:10.1016/j.anai.2010.01.020
[73] Inoue, R., Otsuka, M., Nishio, A. and Ushida, K. (2007) Primary administration of Lactobacillus johnsonii NCC533 in weaning period suppresses the elevation of proinflammatory cytokines and CD86 gene expressions in skin lesions in NC/Nga mice. FEMS Immunology and Medical Microbiology, 50, 67-76. doi:10.1111/j.1574-695X.2007.00233.X

[74] Marschan, E., Kuitunen, M., Kukkonen, K., et al. (2008) Probiotics in infancy induce protective immune profiles that are characteristic for chronic low-grade inflammation. Clinical \& Experimental Allergy, 38, 611-618. doi:10.1111/j.1365-2222.2008.02942.x

[75] Kobayashi, T., Suzuki, T., Kaji, R., et al. (2012) Probiotic upregulation of peripheral IL-17 responses does not exacerbate neurological symptoms in experimental autoimmune encephalomyelitis mouse models. Immunopharmacology and Immunotoxicology, 34, 423-433. doi: $10.3109 / 08923973.2010 .617755$

[76] So, J.S., Kwon, H.K., Lee, C.G., et al. (2008) Lactobacillus casei suppresses experimental arthritis by down-regulating T helper 1 effector functions. Molecular Immunolo$g y$, 45, 2690-2699. doi:10.1016/j.molimm.2007.12.010

[77] Lavasani, S., Dzhambazov, B., Nouri, M., et al. (2010) A novel probiotic mixture exerts a therapeutic effect on experimental autoimmune encephalomyelitis mediated by IL-10 producing regulatory T cells. PLoS ONE, 5, e9009. doi:10.1371/journal.pone.0009009

[78] Niers, L.E., Hoekstra, M.O., Timmerman, H.M., et al. (2007) Selection of probiotic bacteria for prevention of allergic diseases: Immunomodulation of neonatal dendritic cells. Clinical \& Experimental Immunology, 149, 344 352. doi:10.1111/j.1365-2249.2007.03421.x

[79] Hart, A.L., Lammers, K., Brigidi, P., et al. (2004) Modulation of human dendritic cell phenotype and function by probiotic bacteria. Gut, 53, 1602-1609. doi:10.1136/gut.2003.037325

[80] Smits, H.H., Engering, A., Van Der Kleij, D., et al. (2005) Selective probiotic bacteria induce IL-10-producing regulatory $\mathrm{T}$ cells in vitro by modulating dendritic cell function through dendritic cell-specific intercellular adhesion molecule 3-grabbing nonintegrin. Journal of Allergy and Clinical Immunology, 115, 1260-1267. doi:10.1016/j.jaci.2005.03.036

[81] Issazadeh-Navikas, S., Teimer, R. and Bockermann, R. (2012) Influence of dietary components on regulatory $\mathrm{T}$ cells. Molecular Medicine, 18, 95-110. doi:10.2119/molmed.2011.00311

[82] Feleszko, W., Jaworska, J., Rha, R.D., et al. (2007) Probiotic-induced suppression of allergic sensitization and airway inflammation is associated with an increase of $\mathrm{T}$ regulatory-dependent mechanisms in a murine model of asthma. Clinical \& Experimental Allergy, 37, 498-505. doi:10.1111/j.1365-2222.2006.02629.x

[83] Di Giacinto, C., Marinaro, M., Sanchez, M., et al. (2005) Probiotics ameliorate recurrent Th1-mediated murine colitis by inducing IL-10 and IL-10-dependent TGF-betabearing regulatory cells. The Journal of Immunology, 174, 3237-3246.

[84] Hacini-Rachinel, F., Gheit, H., Le Luduec, J.B., et al. 
(2009) Oral probiotic control skin inflammation by acting on both effector and regulatory T cells. PLOS ONE, 4, e4903. doi:10.1371/journal.pone.0004903

[85] Fujimura, T., Okuyama, R., Ito, Y. and Aiba, S. (2008) Profiles of Foxp $3^{+}$regulatory $\mathrm{T}$ cells in eczematous dermatitis, psoriasis vulgaris and mycosis fungoides. British Journal of Dermatology, 158, 1256-1263. doi:10.1111/j.1365-2133.2008.08504.x

[86] Kwon, H.K., Lee, C.G., So, J.S., et al. (2010) Generation of regulatory dendritic cells and $\mathrm{CD} 4^{+} \mathrm{Foxp}^{+} \mathrm{T}$ cells by probiotics administration suppresses immune disorders. Proceedings of the National Academy of Sciences of the United States of America, 107, 2159-2164. doi:10.1073/pnas.0904055107

[87] Taylor, A.L., Hale, J., Hales, B.J., et al. (2007) FOXP3 mRNA expression at 6 months of age is higher in infants who develop atopic dermatitis, but is not affected by giving probiotics from birth. Pediatric Allergy and Immunology, 18, 10-19. doi:10.1111/j.1399-3038.2006.00483.x

[88] Weise, C., Zhu, Y., Ernst, D., et al. (2011) Oral administration of Escherichia coli Nissle 1917 prevents allergen-induced dermatitis in mice. Experimental Dermatology, 20, 805-809. doi:10.1111/j.1600-0625.2011.01326.x

[89] Gerasimov, S.V., Vasjuta, V.V., Myhovych, O.O. and Bondarchuk, L.I. (2010) Probiotic supplement reduces atopic dermatitis in preschool children: A randomized, double-blind, placebo-controlled, clinical trial. American Journal of Clinical Dermatology, 11, 351-361. doi:10.2165/11531420-000000000-00000

[90] Chapat, L., Chemin, K., Dubois, B., et al. (2004) Lactobacillus casei reduces $\mathrm{CD}^{+} \mathrm{T}$ cell-mediated skin inflam- mation. European Journal of Immunology, 34, 2520-2528. doi:10.1002/eji.200425139

[91] Roessler, A., Friedrich, U., Vogelsang, H., et al. (2008) The immune system in healthy adults and patients with atopic dermatitis seems to be affected differently by a probiotic intervention. Clinical \& Experimental Allergy, 38, 93-102.

[92] Gareau, M.G., Sherman, P.M. and Walker, W.A. (2010) Probiotics and the gut microbiota in intestinal health and disease. Nature Reviews Gastroenterology \& Hepatology, 7, 503-514. doi:10.1038/nrgastro.2010.117

[93] Rachmilewitz, D., Katakura, K., Karmeli, F., et al. (2004) Toll-like receptor 9 signaling mediates the anti-inflammatory effects of probiotics in murine experimental colitis. Gastroenterology, 126, 520-528. doi:10.1053/j.gastro.2003.11.019

[94] Hoarau, C., Lagaraine, C., Martin, L., et al. (2006) Supernatant of Bifidobacterium breve induces dendritic cell maturation, activation, and survival through a Toll-like receptor 2 pathway. Journal of Allergy and Clinical Immunology, 117, 696-702. doi:10.1016/j.jaci.2005.10.043

[95] Forsythe, P., Inman, M.D. and Bienenstock, J. (2007) Oral treatment with live Lactobacillus reuteri inhibits the allergic airway response in mice. American Journal of Respiratory and Critical Care Medicine, 175, 561-569. doi:10.1164/rccm.200606-8210C

[96] Aumeunier, A., Grela, F., Ramadan, A., et al. (2010) Systemic Toll-like receptor stimulation suppresses experimental allergic asthma and autoimmune diabetes in NOD mice. PLoS ONE, 5, e11484. doi:10.1371/journal.pone.0011484 